\title{
FORECAST ESTIMATES OF FAR EASTERN EXPORT TREPANG TO CHINA
}

\author{
Valentina V. Zhokhova $^{1 *}$, Natalya P. Belozertseva ${ }^{1}$, Natalya A. Yurchenko ${ }^{1}$ \\ ${ }^{I *}$ Vladivostok State University of Economics and Service, Russian; \\ *Corresponding Author Valentina V. Zhokhova, e-mail: valentina.zhokhova@gmail.com; \\ Belozertseva.NP@vvsu.ru; Natalya.Yurchenko@vvsu.ru;
}

Received November 2021; Accepted December 2021; Published January 2022;

DOI: https://doi.org/10.31407/ijees12.120

\begin{abstract}
Foreign trade plays a significant role in the Russian economy. The development of Russia's foreign trade turnover has recently been characterized by an upward trend. Russia's trading partners in the seafood market have become more active. In this article, the study of the export market of the Far Eastern mariculture is considered. The purpose of the study: to identify the main participants in the seafood market in the Primorsky Territory and to make forecasts of the export opportunities of trepang producers to China. For the study and analysis of export forecasting, the extrapolation method was used. One of the tasks that arise when analyzing the dynamics of series in extrapolation is to establish the regularity of changes in the levels of the studied indicator over time. When analyzing the statistical basic indicators, it was noted that the levels of the analyzed series undergo various changes - both increase and decrease, therefore, when predicting the analyzed indicators, we can only talk about the general trend of the development of the studied phenomenon, or about the trend to increase or decrease. Therefore, for the calculation of forecast estimates of export indicators of trepang in the region, the extrapolation method was chosen by means of analytical alignment of the dynamic series, i.e., the construction of certain trend equations that would mathematically describe the trend in the development of export opportunities of producers of trepang in Primorye over time. The conducted research contains up-to-date information about the main participants of the Russian and Chinese markets of the Far Eastern trepang; analysis of the export opportunities of trepang producers in the Primorsky Territory. The article presents the forecast estimates of the export dynamics of the analyzed product for the period 2021-2023 in physical and value terms.
\end{abstract}

Key words: mariculture, seafood, trepang, extrapolation, forecasting, region, Primorsky Krai. 